1243

\section{PARAMETERS ASSOCIATED WITH DURATION OF INTENSIVE CARE UNIT STAY IN CRITICALLY ILL PAEDIATRIC PATIENTS WITH H1N1 INFECTION}

S. Stabouli ${ }^{1}$, J. Dotis ${ }^{1}$, A. Violaki ${ }^{1}$, S. Kalamitsou ${ }^{1}$, M. Mitroudi ${ }^{1}$, V. Kotsis ${ }^{2}$, M. Kotsiou ${ }^{1}$

${ }^{1}$ Paediatric Intensive Care Unit, Hippokration General Hospital, Thessaloníki, ${ }^{2} 3$ rd Department of Medicine, Aristotle University of Thessaloniki,

\section{Thessaloniki, Greece}

Objective: To investigate parameters that associate with duration of intensive care stay in children with H1N1 infection, requiring paediatric intensive care unit (PICU) admission in a tertiary hospital.

Patients and methods: All patients with H1N1 infection, confirmed by polymerase chain reaction, admitted to PICU from 01-11-2009 to 28-02-2010 were included in the study. Clinical and epidemiologic characteristics, treatment, and outcomes were collected from all patients.

Results: The study population was consisted of 7 girls and 3 boys, age range 0.5-14.5 years. All patients required mechanical ventilation. Mean duration of intensive care unit stay was $34.7 \pm 28.7$ days and mean duration of mechanical ventilation was $32.5 \pm 27.7$ days. Hypoxemia was the prominent cause for intubation and mechanical ventilation in the $80 \%$ of the subjects. Mean duration of high $\mathrm{O}_{2}$ administration with $\mathrm{FiO} 2>60 \%$ was $14.1 \pm 15.4$ days. $60 \%$ of the patients presented bacterial superinfections at $11.6 \pm 3.6$ days of illness. In multivariate linear regression analysis with dependent variable duration of PICU stay and independent variables age, day of illness at admission in PICU and initiation of mechanical ventilation, the number of risk factors for severe disease, biochemical tests and blood gas results at admission, days of virus shedding and occurrence of bacterial superinfections, the parameters that were independently associated with duration of PICU stay were $\mathrm{pO}_{2}$ at admission to $\mathrm{PICU}\left(\mathrm{R}^{2}=0.81, \mathrm{P}<0.05\right)$ and the occurrence of bacterial superinfections $\left(R^{2}=0.99, P<0.01\right)$.

Conclusions: Hypoxemia at admission to PICU and bacterial superinfections are associated with prolonged duration of PICU stay in critically ill children with $\mathrm{H} 1 \mathrm{~N} 1$ infection.

\section{4}

\section{PROGNOSIS UTILITY OF EARLY ACUTE KIDNEY INJURY TO PREDICT LONG ICU STAY}

J. Lorente Romero ${ }^{1}$, A.J. Alcaraz Romero², J. del Castillo Peral' $^{2}$, N. Gil Villanueva ${ }^{1}$, A. Rodríguez Sánchez de la Blanca², E. Sanavia Morán², M.A. Gil-Ruíz Gil-Esparza², B. Bernardo Atienza1

${ }^{1}$ Servicio de Cuidados Intensivos Neonatales,

${ }^{2}$ Servicio de Cuidados Intensivos Pediátricos, Hospital General Universitario Gregorio Marañon, Madrid, Spain

Objetive: To evaluate the ability of the paediatric RIFLE (pRIFLE) criteria in early postoperative period to determine longer Intensive Care Unit (ICU) stays and mechanical ventilation (MV) time after open heart surgery (OHS).

Methods: Retrospective study including children undergoing cardiopulmonary bypass during 4 years. Demographic variables, clinical and surgical-related aggressions and postoperative data were collected. Early acute kidney injury (AKI) (during first 48 postoperative hours) was assessed with pRIFLE criteria. Patient with length of stay (LOS) $>12$ days were considered as long-stay patients (LSP).

Results: 417 patients were included. Median age: 6 months (24.9\% neonate patients). Early AKI criteria fulfilled by 107 patients (categories: Risk 42; Injury 20; Failure 47). 133 children had AKI sometime during the period studied. 61 required renal replacement therapy. 33 children died (7.9\%), 128 had a MV time $>7$ days and 139 were considered LSP. Children with early AKI were younger $(13 \pm 29$ vs $35 \pm 52$ months, $P<0.001)$, had undergone longer CPB (174 \pm 77 vs $118 \pm 53$ minutes), more use of circulatory arrest ( $57 \%$ vs $29 \%$ ), higher rate of LSP $(70.9 \%$ vs $21.6 \%)$ and of $M V>7$ days $(70 \%$ vs $18 \%)$ $[P<0.001]$. Early AKI was independently associated with longer ICU LOS (OR 4.7, IC95\% 2.6-8.6, P< 0.001 ) and MV $>7$ days (OR 5.7, IC95\% 3.1-10.4, $\mathrm{P}<0.001)$ adjusting for age, CPB time, presence of TCA and RACHS-1.

Conclusions: Early AKI when evaluated with the RIFLE criteria can predict prolonged ICU stay and need of prolonged mechanical ventilation. 